\title{
Hypomagnesaemia and hypocalcaemia in a patient with ovarian carcinoma
}

\author{
G.P. Leese, R.T. Jung and M.C.K. Browning ${ }^{1}$ \\ Departments of Medicine and ${ }^{1}$ Biochemical Medicine, Ninewells Hospital and Medical School, Dundee \\ DDI $9 S Y, U K$
}

\begin{abstract}
Summary: A patient with disseminated ovarian carcinoma presented with symptoms of hypocalcaemia secondary to hypomagnesaemia. The low serum magnesium $(0.4 \mathrm{mmol} / \mathrm{l})$ appeared to be due to renal leakage with no evidence of ureteric obstruction or hydronephrosis on intravenous urogram. Parathyroid hormone activity (serum levels and cAMP response) was normal, despite hypomagnesaemia. The patient's complaints resolved after magnesium and calcium supplementation. Hypomagnesaemia of malignancy is a rare but important complication, and is both poorly recognized and understood.
\end{abstract}

\section{Introduction}

Carcinomatosis is most commonly associated with hypercalcaemia, but has been reported with a low serum ionized calcium. ${ }^{1}$ In such cases the hypocalcaemia is usually secondary to the effects of drugs, for example, cytotoxics, aminoglycosides, or osteoblastic bony metastases. Hypomagnesaemia can occasionally cause hypocalcaemia. ${ }^{1}$ We present a patient who had disseminated adenocarcinoma associated with hypomagnesaemia which caused symptomatic hypocalcaemia.

\section{Case report}

A 60 year old woman presented with a 9 month history of general malaise, and a 2 month history of muscle and bone tenderness, with intermittent hand tetany. She complained of $7 \mathrm{~kg}$ weight loss, polyuria and polydipsia and a deterioration of her long-standing psoriasis. She was on no medication, and there was no suggestion of alcohol abuse (including normal MCV and gamma GT measurements). Examination revealed a $4 \mathrm{~cm} \times 3 \mathrm{~cm}$ hard irregular left supraclavicular mass, but with no other lymphadenopathy. She had a positive Chvostek's sign but a negative Trousseau's sign. She was normotensive. There was widespread psoriasis, but no evidence of cataracts or of shortened metacarpals.

Investigation showed: corrected calcium 1.62 $\mathrm{mmol} / 1$ (reference range $2.20-2.60 \mathrm{mmol} / \mathrm{l}$ ) (this

Correspondence: G.P. Leese, B.M.Sc., M.B., Ch.B., M.R.C.P. (UK)

Accepted: 11 December 1992 had been normal 5 years previously); phosphate $1.23 \mathrm{mmol} / 1$ (reference range $0.8-1.5 \mathrm{mmol} / \mathrm{l}) \mathrm{U} / \mathrm{l}$; alkaline phosphate $110 \mathrm{U} / 1$ (reference range $20-$ $120 \mathrm{U} / \mathrm{l}$ ); potassium $4.1 \mathrm{mmol} / \mathrm{l}$; creatinine 135 $\mu \mathrm{mol} / 1$ (reference range $44-140 \mu \mathrm{mol} / 1$ ); magnesium $0.4 \mathrm{mmol} / 1$ (reference range $0.7-1.1 \mathrm{mmol} / \mathrm{l}$ ); bicarbonate $24 \mathrm{mmol} / \mathrm{l}$; random glucose $5.3 \mathrm{mmol} /$ 1; albumin $37 \mathrm{~g} / \mathrm{l}$. When the serum magnesium had been restored (see later) to $0.54 \mathrm{mmol} / \mathrm{l}$ and serum calcium to $2.32 \mathrm{mmol} / 124$ hour urinary collections for calcium $\left(\mathrm{Ca}^{2+}\right)$ and magnesium $\left(\mathrm{Mg}^{2+}\right)$ were $8.71 \mathrm{mmol} / 24$ hour (reference range $2.5-7.5$ ) and $6.36 \mathrm{mmol} / 24$ hour (reference range 3.3-4.9), respectively, reflecting renal leakage of these cations. ${ }^{2}$ Protein excretion was marginally elevated at $280 \mathrm{mg} / 24$ hours whilst sodium $(103 \mathrm{mmol} / 24$ hours) and potassium ( $63 \mathrm{mmol} / 24$ hours) excretion rates were both normal. There was no glycosuria.

Parathyroid hormone (PTH - allegro intact PTH (Nichols Institute, Diagnostics San Juan, Capistrano, CA)) level was elevated at $32 \mathrm{pmol} / \mathrm{l}$ (reference range 1.0-5.0) on admission, falling to $2.8 \mathrm{pmol} / \mathrm{l}$ once the serum $\mathrm{Mg}^{2+}$ and $\mathrm{Ca}^{2+}$ had been corrected. Calcitonin level was normal $(45 \mathrm{nmol})$ and 25 hydroxycholecalciferol concentration was borderline at $6.0 \mathrm{ng} / \mathrm{ml}(N>6.0 \mathrm{ng} / \mathrm{ml})$. There was a normal cAMP response to $200 \mathrm{U}$ intravenous PTH (cAMP rose from 6.1 to $53.8 \mathrm{nmol} / \mathrm{l}$ ), thus revealing no evidence of peripheral resistance to PTH, for example, in pseudohypoparathyroidism.

Fine needle aspiration and subsequent excision of the neck lump revealed a poorly differentiated adenocarcinoma with psammoma bodies. Repeated chest X-ray, gastroscopy, thyroid isotope scan, vaginal ultrasound and isotope bone scan were all 
normal. Intravenous urogram was also normal revealing no evidence of obstruction.

During investigations, the patient complained of increasing suprapubic discomfort, and there was a steady rise in serum creatinine from 135 to $297 \mu \mathrm{mol} / \mathrm{l}$. Laparoscopy and subsequent laparotomy revealed an unresectable disseminated ovarian adenocarcinoma within the pelvis. CA125 levels were elevated. The tumour surrounded the lower ends of both ureters, and a limited attempt was made to debulk the tumour.

Therapy at the time of presentation included an infusion of $40 \mathrm{mmol}$ of i.v. calcium gluconate over 12 hours but this failed to maintain a rise in the serum calcium. However, both serum $\mathrm{Ca}^{2+}$ and $\mathrm{Mg}^{2+}$ concentrations corrected after $80 \mathrm{mmol}$ i.v. magnesium sulphate infusion followed by a further $40 \mathrm{mmol}$ of i.v. calcium gluconate rising to 2.17 $\mathrm{mmol} / 1$ and $0.85 \mathrm{mmol} / 1$, respectively. Serum levels were maintained initially by $4 \mu \mathrm{g}$ of $1-\alpha$-calcidol, later reduced to $1 \mu \mathrm{g}$, and $20 \mathrm{mmol}$ of magnesium glycerophosphate per day orally. Two months later the oral $\mathrm{Mg}^{2+}$ was stopped (but not the 1- $\alpha$ calcidol) but serum $\mathrm{Mg}^{2+}$ levels fell from 0.73 to $0.43 \mathrm{mmol} / 1$ and serum calcium decreased from 2.31 to $1.81 \mathrm{mmol} / \mathrm{l}$, and hence oral magnesium supplements were restarted. Whilst on oral $\mathbf{M g}^{2+}$ and $1-\alpha$-calcidol tablets (without calcium tablets) serum $\mathrm{Mg}^{2+}$ and $\mathrm{Ca}^{2+}$ levels were maintained in the normal range and the patient remained asymptomatic.

\section{Discussion}

Hypocalcaemia is uncommon in patients with malignant disease. An incidence of $1.6 \%$ has been quoted, ${ }^{1}$ but closer analysis of the figures shows that only $0.4 \%$ had a low serum ionized calcium. The incidence of symptomatic hypocalcaemia was even lower. Hypocalcaemia of malignancy was usually due to drugs, osteoblastic metastases (especially breast or prostate) or significant renal failure, ${ }^{1}$ but has also been reported to be due to metastatic invasion of the parathyroid glands. ${ }^{3}$ None of these mechanisms, however, appear relevant in our case. Hypomagnesaemia can cause hypocalcaemia. ${ }^{1}$ Although the incidence of hypomagnesaemia in malignancy is unknown, the incidence in hospitalized patients $(6.9-32 \%)^{4,5}$ is relatively common.

In our patient intravenous calcium therapy did not produce a sustained correction in the serum calcium which was only achieved when intravenous magnesium was given indicating that the hypomag- nesaemia was the primary defect. This was again shown, when oral magnesium supplements were withdrawn, but oral calcium maintained, but both serum calcium and magnesium concentrations fell $\left(\mathrm{Ca}^{2+}\right.$ to $1.81 \mathrm{mmol} / 1 \mathrm{Mg}^{2+}$ to $\left.0.43 \mathrm{mmol} / \mathrm{l}\right)$. The patient appeared to have a renal leakage of $\mathrm{Mg}^{2+}$ with inappropriately high 24 hour urinary $\mathbf{M g}^{2+}$ excretion $^{1}$ when the serum levels were low.

Changes in $\mathrm{Mg}^{2+}$ reabsorption in the loop of Henle provide the normal mechanism for $\mathbf{M g}^{2+}$ homeostasis, ${ }^{6}$ although intestinal absorption is more important in $\mathrm{Ca}^{2+}$ homeostatis. The usual causes of renal tubular magnesium leakage (for example, drugs, alcohol, thyrotoxicosis, diabetes mellitus, hypercalcaemia, renal tubular acidosis and primary hyperaldosteronism ${ }^{7}$ ) were not relevant in this patient. This patient had mild renal failure (creatinine $135 \mu \mathrm{mol} / 1$ on admission), which has been associated with hypomagnesaemia due to renal wastage, ${ }^{7}$ although chronic renal failure more commonly causes hypermagnesaemia. The cause of the renal failure is unclear, as IVU demonstrated no gross ureteric obstruction. Metabolites such as lactate which are implicated in renal $\mathrm{Mg}^{2+}$ leakage in alcoholics, ${ }^{8}$ and have been reported raised in patients with disseminated malignancy. ${ }^{9}$ Lactate levels were not measured, but as the patient was not significantly acidotic $\left(\mathrm{HCO}_{3}^{-}=24 \mathrm{mmol} / \mathrm{l}\right)$ it was unlikely to be an important factor.

In hypomagnesaemic hypocalcaemia, PTH con centration is usually low or normal ${ }^{10,11}$ (when elevated levels would be expected) and there is also a peripheral resistance to PTH. ${ }^{12-14}$ Hypomagnesaemic hypocalcaemia has been reported in some patients with nonovarian malignant tumours (carcinoma of prostate,${ }^{15,16}$ hepatocellular carcinoma ${ }^{10}$ ) but in such patients the hypomagnesaemia limits the usual PTH response to hypocalcaemia. ${ }^{10}$ In our case the hypomagnesaemia did not seem to affect PTH pathways since a physiological secondary hyperparathyroidism to the hypocalcaemia occurred, and there was a normal end organ cAMP response to PTH. Hypomagnesaemia has also been shown to produce hypocalcaemia by a PTHindependent direct effect on bone, ${ }^{11}$ and this may have been the mechanism in our patient.

We present a patient with disseminated ovarian carcinoma causing hypomagnesaemia presumably due to renal leakage. The patient developed symptomatic hypocalcaemia despite an apparently normally acting parathyroid axis. Magnesium supplements corrected the hypocalcaemia. Hypomagnesaemia should always be considered in patients with malignancy who develop signs of hypocalcaemia. 
References

1. Blomquist, C. A hospital survey of hypocalcemia in patients with malignant disease. Acta Med Scand 1986, 220: 167-173.

2. Shills, M.E. Experimental human magnesium depletion. Medicine 1969, 118: 61-85.

3. Goddard, C., Mbauu, A. \& Evanson, J. Symptomatic hypocalcemia associated with metastatic invasion of the parathyroid glands. Br J Hosp Med 1990, 43: 72.

4. Whang, R., Oei, T.O., Aikawa, J.K., Watanabe, A. \& Vannatta, J. Predictors of clinical hypomagnesaemia, hypokalaemia, hypophosphataemia, hyponatraemia and hypocalcaemia. Arch Int Med 1984, 144: 1794-1796.

5. Kingston, M.E., Al-Sibai, M.B. \& Skooge, W.C. Clinical manifestations of hypomagnesaemia. Crit Care Med 1986, 14: $950-954$.

6. Quamme, G. Renal handling of magnesium: drug and hormone interactions. Magnesium 1986, 5: 248-272.

7. Massry, S.G. Hypomagnesaemia and hypermagnesaemia. In: Suki, W.N. \& Massry, S.G. (eds): Therapy of Renal Diseases. Martinus Nijhoff, Massachusetts, 1984, pp. 101-105.

8. Cronin, R. \& Knochel, J. Magnesium deficiency. Adv Int Med 1983, 28: 509-533.

9. Clark, A. Glucose homeostasis. In: Jung, R.T. \& Sikora, K. (eds) Endocrine Problems in Cancer. Heinemann, London, 1984, pp. $71-88$.
10. Maguire, P.J. \& MacDonald, J.S. Hypocalcaemia associated with a calcitonin producing hepatocellular carcinoma. Arch Int Med 1981, 141: 687-688.

11. Graber, M.L. \& Schulman, G. Hypomagnesaemic hypocalcaemia. Independent of parathyroid hormone. Ann Intern Med 1986, 104: 808-815.

12. Jacob, A.I., Pennell, J.P., Lambert, P.W. \& Gavellas, G. Vitamin D metabolites and parathyroid hormone in hypomagnesaemic hypocalcaemia. Min Electrolyte Metab 1981, 6: 316-322.

13. Fuss, M. Cogan, E., Gillet, C. et al. Magnesium administration reverses the hypocalcaemia secondary to hypomagnesaemia despite low circulating levels of 25-hydroxy vitamin D and 1,25-dihydroxy vitamin D. Clin Endocrinol 1985, 22: 807-815.

14. Rude, R.K. \& Singer, F.R. Magnesium deficiency and excess. Ann Rev Med 1981, 32: 245-259.

15. Tommaso, C.L. \& Tucci, J.R. Metabolic studies in a case of hypocalcaemia and osteoblastic metastases. Arch Int Med 1981, 139: 238-241.

16. Kukreja, S.C., Shunmugam, A. \& Lad, T.E. Hypocalcaemia in patients with prostate carcinoma. Calcif Tissue Int 1988 , 43: $340-345$.

\title{
Primary lymphoma of the gallbladder
}

\author{
E.P. Friedman, E. Lazda, D. Grant and J. Davis
}

Department of Imaging and Histopathology Department, The Whittington Hospital, Highgate Hill, London N19 5 NF, UK

\begin{abstract}
Summary: A case of primary lymphoma of the gallbladder is described which is rare in the medical literature. A 76 year old man presented with acute cholecystitis and septicaemia. Investigation showed a lung abscess and a gallbladder mass. The mass was thought to be an empyema and cholecystostomy was performed. Biopsy of the gallbladder wall showed high-grade B cell lymphoma. The patient unfortunately succumbed to overwhelming septicaemia in the postoperative period. Postmortem examination confirmed primary lymphoma of the gallbladder without dissemination.
\end{abstract}

\section{Introduction}

Although lymphomas are thought to be primarily tumours of lymph nodes, a substantial proportion arise from other tissues. The percentage of nonHodgkin's lymphoma originating extranodally varies amongst published series from $24 \%^{1}$ to $46 \%{ }^{2}$ In one series of 580 patients with nonHodgkin's lymphoma $41 \%$ had primary extranodal lymphoma of which $36 \%$ arose in the gastrointestinal tract. ${ }^{3}$ Whilst a few cases have been described of primary extranodal lymphoma origi-

Correspondence: E. Friedman, M.R.C.P.

Accepted: 30 November 1992 nating in the pancreas and liver, ${ }^{4}$ the gallbladder as the site of origin is extremely rare. Lymphomatous involvement of the wall of the bile ducts has been described $^{5}$ as well as two cases of extranodal lymphoma originating in the extrahepatic bile ducts. Cholecystitis is a rare presenting feature of lymphoma.

\section{Case report}

A 76 year old man presented with a 6 week history of malaise, weight loss, right upper quadrant pain 